\title{
Inversión y \\ volatilidad financiera en América Latina
}

\section{Graciela Moguillansky}

División de Desarrollo

Económico, CEPAL

gmoguillansky@eclac.cl
La liberalización financiera y la apertura al mercado de capitales permitió atraer la inversión extranjera y expandir la capacidad de financiamiento de los proyectos de inversión, pero al mismo tiempo facilitó la difusión de las crisis financieras originadas dentro o fuera de América Latina, que en la década de 1990 se sucedieron con mayor frecuencia. Esto llevó a estudiar con más detenimiento el impacto de la inestabilidad de los flujos de capital sobre la inversión. Las hipótesis derivadas de los enfoques teóricos fueron contrastadas con ejercicios econométricos que demuestran, por una parte, el impacto positivo de los flujos de capital y, por otra, el impacto negativo de su volatilidad. El estudio abarcó un conjunto importante de países de la región. 
I

\section{Introducción}

La inversión en América Latina en la década de 1990 ha mantenido una tasa inestable de crecimiento y una baja participación en el PIB, no sólo si se compara con los países en desarrollo de alto crecimiento, sino que también con su propio desempeño en los 30 años posteriores a la segunda guerra mundial. Esta evolución se enmarca en un proceso de transformaciones económicas cuyo inicio, en general, se puede situar hacia mediados de la década de 1980 y que se prolongó a lo largo del decenio de 1990, conduciendo a las economías hacia una apertura al comercio y a los flujos financieros internacionales e integrándolas en el proceso de globalización mundial.

En este proceso, mientras el Estado se fue retirando de la producción y restringiendo el financiamiento de la inversión, los actores privados nacionales y extranjeros fueron asumiendo el liderazgo. Pero, a diferencia de lo esperado por los impulsores de las reformas económicas, el modelo de apertura no ha logrado estabilizar el crecimiento ni la tasa de inversión. La hipótesis de este artículo es que, en el contexto del proceso de apertura, la volatilidad de los flujos de capitales ha contrarrestado el beneficio de obtener financiamiento para grandes proyectos de inversión en épocas de liquidez financiera internacional, con el costo de la abrupta reversión de los flujos originada por factores ajenos a la evolución de los fundamentos macroeconómicos de los países. Este costo se ha visto acrecentado por un manejo macroeconómico procíclico.

El argumento y la comprobación empírica de esta hipótesis se desarrollan en las secciones siguientes. Primero se describe el nuevo contexto en que los agentes privados, nacionales y extranjeros toman las decisiones de inversión (sección II). Seguidamente se exponen los factores de incertidumbre que tiñen las decisiones de inversión y que están vinculados al cambio estructural (sección III). Luego se analizan algunos hechos estilizados vinculados a los componentes del financiamiento externo, discriminando entre la volatilidad de la inversión extranjera directa y las restantes transferencias de recursos externos (sección IV); se exponen los mecanismos de transmisión entre la volatilidad de los flujos de capitales y la inversión (sección V); se presentan los resultados de una estimación empírica de la función de inversión y de la prueba de hipótesis del modelo (sección VI), considerando en la especificación determinantes tradicionales a los que se incorpora explícitamente un indicador de volatilidad de los flujos financieros externos. Finalmente, en la sección VII se presentan las conclusiones.

\section{II}

\section{El modelo de crecimiento y el nuevo contexto de la inversión}

Desde una perspectiva histórica, hacia el inicio del nuevo milenio se detecta un fuerte cambio en el modelo de crecimiento de América Latina. La transformación ocurre desde el llamado modelo sustitutivo de importaciones hacia un modelo caracterizado por la apertura comercial, financiera y del mercado de capitales y por la disminución del papel del Estado en la economía como agente productivo, financiero y rector.

$\square$ Este artículo se basa en un texto preparado para servir de apoyo al documento de la CEPAL titulado Globalización y desarrollo, LC/G. 2157 (SES. 29/3), que se presentó en el $29^{\circ}$ período de sesiones de la Comisión, realizado en Brasilia del 6 al 10 de mayo de 2002.
El gráfico 1 muestra la tasa de crecimiento del PIB regional y del coeficiente de inversión desde 1950 hacia adelante (la fecha de inicio fue escogida por la disponibilidad de series homogéneas). En promedio, la región aceleró su tasa de crecimiento de $4.8 \%$ (década de 1950) a $5.7 \%$ (década de 1960) y $5.6 \%$ (década de 1970 ), con un esfuerzo inversor que fue consistentemente mayor en esta última (25\% del PIB). Estos resultados se dieron a pesar de la inestabilidad de la relación de precios del intercambio y de las transferencias netas de recursos externos, cuyo promedio para las décadas de 1950 y 1960 fue negativo. 
GRAFICO 1

América Latina: Crecimiento del PIB y coeficiente de inversión en los últimos 50 años

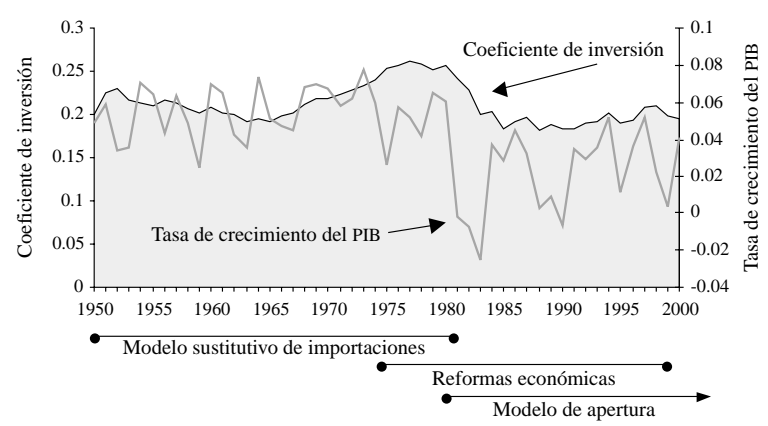

Fuente: CEPAL, División de Desarrollo Económico, elaboración de la autora.

En el decenio de 1970 la región comenzó a experimentar un marcado cambio - sobre todo en algunos países - en parte inducido internamente, por la crisis del modelo sustitutivo, y en parte desde el exterior.

El primer shock petrolero y la consecuente liquidez financiera internacional dieron un respiro a las economías latinoamericanas, permitiéndoles financiar la inversión y crecer con endeudamiento. Pero la crisis de la deuda externa y la reversión de los flujos de capitales - primer impacto regional de la volatilidad de los flujos- golpeó con fuerza a todos los países, incluidos aquéllos que habían iniciado el proceso de liberalización y cuyo sector privado se había endeudado en pro de ganancias de corto plazo.
La década de 1980 , teñida por la turbulencia que dejó la crisis de la deuda externa y por el inicio de las transformaciones estructurales, mostró las tasas de crecimiento más bajas de los últimos cincuenta años, arrasando con muchos de los logros sociales de decenios precedentes. Pero, al mismo tiempo, dio paso a un período de transición hacia un nuevo modelo de crecimiento en que los gobiernos apostaron al sector privado como agente líder del proceso y al desarrollo exportador como clave para una nueva inserción internacional.

Transcurridos más de quince años desde el inicio del proceso de reformas, los resultados no han sido alentadores. La región sigue mostrando una altísima vulnerabilidad en lo comercial y financiero. Son pocos los países en que la inversión ha crecido en el conjunto de sectores de bienes exportables, ${ }^{1}$ mientras que en un número importante de países — principalmente de Sudamérica- el capital se ha dirigido a los sectores exportadores primarios o procesadores de materias primas, cuya extrema volatilidad de precios, al igual que en décadas pasadas, acentúa la debilidad del comercio exterior.

Asimismo, la baja inversión en la manufactura ha hecho disminuir la participación del producto interno bruto industrial en el PIB global y ha deteriorado la balanza comercial del sector (salvo en México y algunos países centroamericanos). El resultado ha sido una tasa de inversión y crecimiento en la década de 1990 inferior a las de los decenios de 1950, 1960 y 1970, y una mayor inestabilidad en el crecimiento (véase nuevamente el gráfico 1), esta vez alimentada también por la volatilidad de los flujos de capital.

\section{III}

\section{El cambio estructural y los factores de incertidumbre vinculados a las decisiones de inversión}

Las reformas económicas en América Latina se iniciaron, en la mayoría de los países de la región, en medio de la turbulencia generada por la crisis de la deuda externa. Varias de las políticas que les dieron forma fueron parte de los procesos de estabilización - la apertura comercial y financiera, por ejemplo, integró el paquete de políticas junto con la introducción de regímenes de ancla cambiaria- y sus efectos en el corto pla- zo se mezclaron, generando señales a veces consistentes y otras inconsistentes con el estímulo inversor.

Si bien las economías avanzaron hacia un nuevo modelo económico, la característica del período 1990-

\footnotetext{
${ }^{1}$ Véase en Moguillansky y Bielschowsky (2000) un análisis detallado de la inversión sectorial en América Latina.
} 
1999 fue la de un proceso de transición. Esto por varias razones: en primer lugar, para los países que iniciaron las reformas estructurales en el decenio de 1990 -Argentina, Brasil, Colombia y Perú - el tiempo transcurrido no ha sido suficiente para consolidar ese nuevo modelo. Por lo tanto, las decisiones de inversión debieron tomarse en un período de especial incertidumbre.

En segundo lugar, las reformas no comenzaron simultáneamente. En general, la apertura comercial fue la primera que se implementó, mientras que las privatizaciones de servicios públicos fueron las últimas. En algunos países las reformas, en su conjunto, se pusieron en marcha de manera simultánea y en otros el proceso se desarrolló lentamente y con diferentes secuencias a lo largo del tiempo, lo que ha dificultado la madurez integral del proceso. Costa Rica y Brasil serían un buen ejemplo de esto último.

En tercer lugar, la evolución de las reformas no fue lineal, lo que expuso a los agentes económicos a reglas del juego cambiantes: piénsese en las sobretasas arancelarias y otras trabas al comercio internacional a las que los países siguen recurriendo en etapas posteriores a cada crisis de balanza de pagos.

En cuarto lugar, el inicio del proceso de reforma, en un contexto de profundo desajuste del sistema de precios relativos y alto grado de inestabilidad económica, llevó a que aquellas industrias que aprendieron rápidamente el manejo financiero de corto plazo pudieran obtener ganancias especulativas o sobrevivir en el mercado, pero no favoreció necesariamente a las empresas más eficientes en sus procesos productivos ni al fortalecimiento de las economías en el largo plazo. $^{2}$

Esta respuesta alimentó la crisis de inicios de los años ochenta y la reversión de los procesos de reforma en varios países - Chile y Argentina fueron claros ejemplos-, lo que se deduce de los aumentos de los aranceles aduaneros, la imposición de nuevos controles al mercado de capitales y la intervención estatal en el sistema financiero y en las empresas relacionadas con los bancos.

La existencia de un mercado de capitales abierto y de sistemas financieros nacionales institucionalmente frágiles no sólo contribuyó a la desestabilización, sino que además cuestionó las políticas macroeconómicas y dejó en claro la debilidad de las reformas implementadas. ${ }^{3}$ Como los fenómenos descritos se repitieron (en México tras la crisis del tequila, en Brasil y Argentina después de la crisis asiática y la crisis rusa), tomó peso una interrogante: si algunos aspectos de las reformas han contribuido a debilitar a los países en el contexto de la globalización e internacionalización económica que caracterizan al mundo actual.

La desregulación inicial de los mercados financieros, de valores y de servicios públicos ha venido creando problemas que con el tiempo han obligado a los gobiernos a regular y a modificar y fortalecer las legislaciones y las instituciones. Las reformas se fueron reorientando, creando nuevos cuadros de incertidumbre entre los agentes económicos, cuyas conductas no terminan de definirse.

La liberalización financiera entregó el marco en el cual los proyectos de inversión fueron promovidos u obstaculizados, dependiendo del tipo de empresa y sector. Las crisis financieras del decenio de 1990 involucraron a todos los países de la región debido a la percepción que los inversionistas tenían del riesgo por contagio. La salida de capitales interrumpió así repetidamente tanto el crecimiento como el financiamiento de la inversión. Por otra parte, los lazos entre lo real y lo financiero se mezclan a tal punto que una crisis que comienza en el sector real rápidamente se propaga al financiero y viceversa, potenciando sus adversos efectos.

Este cuadro de reformas estructurales, cambios en las reglas del juego, transferencias de capital entre sectores, shocks externos de nuevo tipo amplificados por la apertura financiera y del mercado de capitales y, en general, por el fenómeno de la globalización, no sólo representó el nuevo contexto, sino que también se tradujo en señales que en ciertos casos incentivaron y, en otros, desalentaron las decisiones de inversión. En este artículo escogimos uno de estos elementos: la inestabilidad de los flujos de capital y del financiamiento, con el fin de analizar con mayor profundidad su impacto sobre la inversión.

\footnotetext{
${ }^{2}$ Al respecto véase Frenkel (1982); Frenkel y Damill (1987) y Kosacoff (1998).
}

\footnotetext{
3 Véase más antecedentes en Ocampo, Bajraj y Martin (coords., 2001).
} 


\section{IV}

\section{Flujos financieros e inversión: algunos fenómenos estilizados}

Durante las décadas de 1950 y 1960, las corrientes de capitales a los países en desarrollo estaban atadas al financiamiento del comercio internacional, a inversiones específicas que financiaban actividades reales, o bien correspondían a flujos de capitales oficiales de organismos, tanto multilaterales como bilaterales, que compensaban las perturbaciones de la relación de precios del intercambio. Hacia fines de la década de 1960 e inicios de la de 1970, con la aparición de los eurodólares, los créditos de la banca privada internacional se volcaron hacia América Latina. La crisis de la deuda externa y la búsqueda de alternativas para enfrentarla - especialmente el Plan Brady - dieron origen a los mercados de instrumentos de deuda y al mercado de capitales en la región.

En promedio, la transferencia neta de recursos en los decenios de 1950 y 1960 fue negativa (gráfico 2). $\mathrm{Al}$ analizar las cifras absolutas, no sólo llama la atención el incremento posterior de los flujos de capitales, que pasaron de 4 mil millones de dólares en 1970 a un máximo de 142 mil millones en 1998, sino que también el cambio de su composición (cuadro 1). La participación de los flujos oficiales cayó de $23 \%$ del total en 1970 a $0.4 \%$ en 2000 , mientras que en las corrientes de capitales privados se destacó una mayor participación de los flujos de cartera (acciones y bonos), que pasó de $1.3 \%$ a $20 \%$ entre 1970 y 2000 , seguida por la de la inversión extranjera directa, que aumentó de $25 \%$ a $74 \%$ en ese mismo período.

El 80\% del total de la inversión extranjera directa se concentró en cuatro países (Argentina, Brasil, Chile y México), aunque en términos de porcentaje del PIB el impacto sobre los países pequeños fue superior. Sendos estudios (Ocampo, Bajraj y Martin (coords.) 2001 y CEPAL 2001) han identificado las motivaciones de las diferentes estrategias empresariales que han impulsado estas inversiones:

i) la búsqueda de competitividad en industrias dinámicas, como la automotriz, la electrónica y la de vestuario (éste fue especialmente el caso de las empresas trasnacionales en México y el Caribe);

ii) la reestructuración y modernización de unidades productivas en mercados locales y regionales;
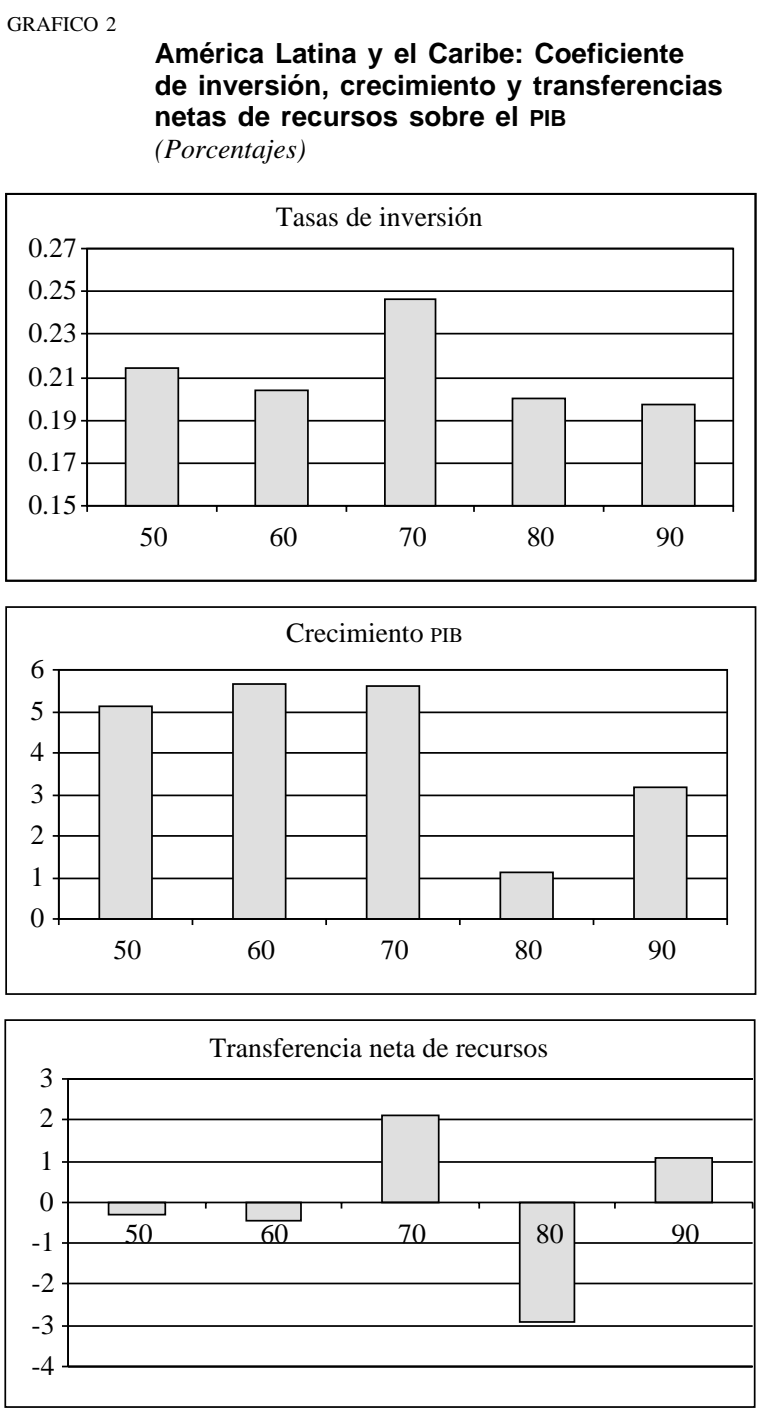

Fuente: CEPAL, División de Desarrollo Económico, elaboración de la autora.

iii) la profundización de inversiones en sectores con ventajas comparativas naturales (minerales e hidrocarburos), y

iv) la adquisición y modernización de sectores de infraestructura con el fin de proyectarse hacia los mercados regionales. 


\begin{tabular}{|c|c|c|c|c|c|c|c|}
\hline & 1970 & 1980 & 1990 & 1995 & 1998 & 1999 & 2000 \\
\hline Total (miles de millones de dólares) & 4.2 & 29.9 & 21.8 & 75.4 & 142.6 & 116.5 & 102.4 \\
\hline Flujos oficiales & 1.0 & 5.3 & 9.2 & 12.6 & 12.3 & 5.2 & 0.4 \\
\hline Flujos privados & 3.3 & 24.6 & 12.6 & 62.8 & 130.2 & 111.3 & 102.0 \\
\hline Inversión extranjera directa & 1.1 & 6.1 & 8.2 & 29.8 & 72.1 & 90.4 & 76.2 \\
\hline Inversión accionaria & 0.0 & 0.0 & 1.1 & 7.6 & 1.7 & 3.9 & 9.9 \\
\hline Bonos & 0.1 & 0.8 & 0.1 & 11.5 & 18.3 & 19.1 & 11.0 \\
\hline Banca comercial y otros créditos & 2.1 & 17.7 & 3.2 & 13.9 & 38.1 & -2.0 & 5.0 \\
\hline Total (porcentajes) & 100 & 100 & 100 & 100 & 100 & 100 & 100 \\
\hline Flujos oficiales & 23.2 & 17.7 & 42.1 & 16.8 & 8.7 & 4.5 & 0.4 \\
\hline Flujos privados & 76.8 & 82.3 & 57.9 & 83.2 & 91.3 & 95.5 & 99.6 \\
\hline Inversión extranjera directa & 25.8 & 20.5 & 37.6 & 39.5 & 50.5 & 77.5 & 74.4 \\
\hline Inversión accionaria & 0.0 & 0.0 & 5.1 & 10.1 & 1.2 & 3.3 & 9.6 \\
\hline Bonos & 1.3 & 2.7 & 0.5 & 15.2 & 12.8 & 16.4 & 10.7 \\
\hline Banca comercial y otros créditos & 49.7 & 59.1 & 14.8 & 18.4 & 26.7 & -1.7 & 4.9 \\
\hline
\end{tabular}

Fuente: Banco Mundial (2001).

Un porcentaje significativo de la inversión extranjera directa que fluyó hacia América Latina en la última década correspondió a fusiones, adquisiciones y privatizaciones. La cifra estimada para los años 19992000 es de 50\%. Pero las compras de empresas fueron acompañadas de capitales para expandir la capacidad productiva, modernizar equipos e incorporar tecnología de frontera, sobre todo en los sectores de infraestructura (electricidad y telecomunicaciones), contribuyendo así a incrementar la competitividad sistémica de la región.

En América Latina, la inversión extranjera directa ha sido menos volátil que el conjunto de transferencias netas de capital, como lo muestra el coeficiente de variación (cuadro 2). Estas cifras son consistentes con las conclusiones del estudio efectuado por Sarno y Taylor (1999), quienes encontraron que la inversión extranjera directa es más sensible a los movimientos estructurales de largo plazo, relación que no se observa en otras formas de financiamiento.

Hausmann y Fernández-Arias (2000a y 2000b) y Lipsey (2001) también concluyeron que los flujos de

CUADRO 2

\section{América Latina: Coeficiente de variación de la inversión extranjera directa y de la transferencia neta de recursos externos (Promedio del período)}

1980-1985 1986-1989 1990-1995 1996-2000

\begin{tabular}{lllll}
\hline Inversión extranjera directa & 0.22 & 0.35 & 0.23 & 0.24 \\
Transferencia neta de recursos & 1.51 & 0.24 & 1.45 & 1.31 \\
\hline
\end{tabular}

Fuente: CEPAL, Balanza de pagos de 19 países de América Latina.
IED son de menor riesgo que la deuda u otros flujos financieros, porque no inducen las crisis. ${ }^{4}$

Los flujos de cartera y la deuda con el sistema financiero internacional, por el contrario, mostraron en la década de 1990 una gran volatilidad (cuadro 3), retornando a los países de origen no sólo frente a condiciones internas de inestabilidad, sino que frente a perturbaciones ocurridas en otros países o regiones - tal fue el caso de la crisis del tequila y su repercusión en Brasil y Argentina, de la crisis asiática y su repercusión en el Cono Sur, o de la crisis rusa y su repercusión regional. Estos flujos se han destinado sólo en parte al financiamiento de la inversión, lo que se comprueba por la tendencia a sustituir ahorro interno por ahorro externo (Uthoff y Titelman, 1997).

CUADRO 3

América Latina: Coeficiente de variación de los flujos financieros en la década de $\mathbf{1 9 9 0}$ (Promedio del período)

\begin{tabular}{lcc}
\hline & $1990-1995$ & $1996-2000$ \\
\hline Inversión extranjera directa & 0.23 & 0.24 \\
Inversión accionaria & 0.62 & 0.69 \\
Bonos & 0.64 & 0.58 \\
Banca comercial y otros créditos & 1.03 & 0.89 \\
\hline
\end{tabular}

Fuente: CEPAL, División de Desarrollo Económico, elaboración de la autora sobre la base de Banco Mundial (2001).

\footnotetext{
${ }^{4}$ Los resultados de estos estudios contrastan con los de Claessens, Dooley y Warner (1995), quienes encontraron que la IED y los flujos de capitales de corto plazo tienen el mismo grado de volatilidad, aunque las observaciones que efectuaron sólo incluyen unos pocos países.
} 
GRAFICO 3

América Latina: Volatilidad de la transferencia neta de recursos y coeficiente de inversión sobre el PIB

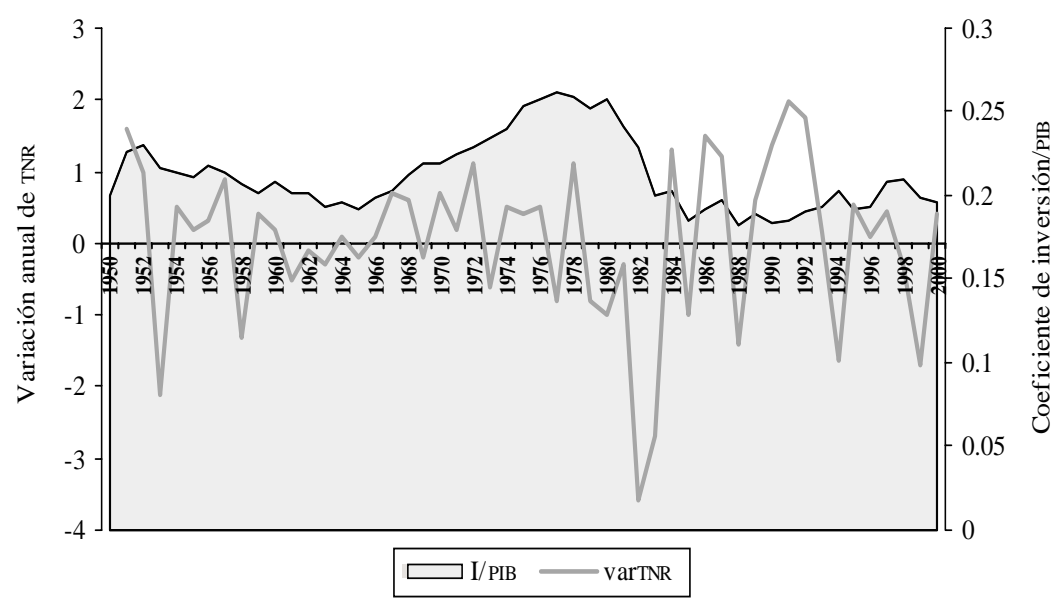

Fuente: CEPAL, División de Desarrollo Económico, elaboración de la autora.

En el gráfico 3 se observa que existe una relación inversa entre la volatilidad de los flujos de financiamiento y el coeficiente de inversión medio para América Latina. El período de menor volatilidad —décadas de 1950 a 1970 - coincide con un mayor coeficiente de inversión sobre el PIB. La correlación entre ambas variables es negativa: -22\% para el período 1950-2000, aumentando a $-44 \%$ entre 1980 y 2000.

\section{Mecanismos de transmisión entre la variación de los flujos de capital y la inversión}

En un contexto de apertura y liberalización financiera, la variación de los flujos de capital internacionales incide sobre los sectores monetario y cambiario y sobre el gasto, pero la forma en que se transmite depende de los supuestos del modelo y, en particular, del grado de apertura de la cuenta de capitales y del régimen cambiario imperante.

Para simplificar, partamos por un modelo muy general y simple: ${ }^{5}$

$$
i=i^{*}+\left(E^{e}-E\right) / E+\lambda \varphi
$$

La ecuación [1] muestra que la tasa de interés interna $i$ depende de la tasa de interés internacional $i^{*}$,

\footnotetext{
${ }^{5}$ El modelo se basa en las elaboraciones de Claassen (1997) y de Krugman y Obstfeld (1995).
}

de la tasa de depreciación cambiaria esperada $\left(E^{e}-E\right) / E$ y de una variable $\varphi$, que pudiera representar el premio exigido por los inversionistas extranjeros frente al riesgo de los países en desarrollo (riesgo país).

Si existen expectativas inflacionarias $\Pi^{e}$, reemplazando $i$ por $\left(r+\Pi^{e}\right)$ e $i^{*}$ por $\left(r^{*}+\Pi^{e}\right)$ se obtiene la ecuación correspondiente a la tasa de interés real

$$
r=r^{*}+\left(e^{e}-e\right) / e+\lambda \varphi
$$

(equilibrio en el mercado financiero)

siendo $e$ el tipo de cambio real y $e^{e}$ el tipo de cambio real esperado.

Entonces [1] puede ser escrito como:

$$
e=e^{e} /\left(1+r-r^{*}-\lambda \varphi\right)
$$


Estas ecuaciones representan la aproximación financiera a la determinación del tipo de cambio real (enfoque monetario), que destaca justamente el papel que éste desempeña en equilibrar las rentabilidades esperadas de los activos financieros internos y externos en términos de tasas de interés de paridad.

En una economía pequeña y abierta, con sustitución perfecta entre activos financieros nacionales e internacionales, cualquier diferencia de rentabilidad entre tales activos es inmediatamente eliminada por los movimientos del tipo de cambio. La diferencia en las rentabilidades esperadas da origen a los flujos de capitales. La reacción inmediata del tipo de cambio elimina la diferencia entre las tasas de interés, volviendo a equilibrar la tasa interna y externa (tasa de interés de paridad). Este es un modelo de corto plazo que puede explicar las variaciones diarias, semanales o mensuales en el tipo de cambio, cuando la autoridad económica no interviene en absoluto en el mercado cambiario.

En un enfoque macroeconómico de más largo plazo, en que se introduce la economía real, los movimientos del tipo de cambio real contribuyen, junto con otras variables, a equilibrar el mercado de bienes. El equilibrio macroeconómico a su vez sirve de ancla para las expectativas cambiarias en el mercado financiero. Pero también, a menos que haya inmovilidad de capitales, la determinación macroeconómica del tipo de cambio puede ir acompañada por un déficit o superávit en la cuenta corriente de la balanza de pagos, lo que reflejaría un cambio en las tenencias netas de activos financieros. Para completar el modelo entonces agregamos la ecuación referida al mercado de bienes:

$$
y=A(r, m)+B(A, e)
$$

(equilibrio en el mercado de bienes)

donde $y$ representa la oferta interna, $A$ representa la demanda de bienes nacionales e importados (consumo más inversión) que depende negativamente de la evolución de la tasa de interés real y positivamente (efecto riqueza) de la liquidez real $m$, y $B$ representa el saldo en la balanza comercial, que es función del nivel de absorción y del tipo de cambio real.

Finalmente, la ecuación que equilibra el mercado monetario es:

$$
\begin{gathered}
m=M / P=L(y, r) \text { (equilibrio en el } \\
\text { mercado monetario) }
\end{gathered}
$$

donde $M$ representa la oferta de dinero y $P$ el nivel de precios.
Con este modelo es posible determinar los mecanismos de transmisión (variación en la tasa de interés interna, expectativas de devaluación o revaluación, presiones inflacionarias y variación de la demanda) que actúan frente a fluctuaciones de las corrientes internacionales de capitales y que terminan incidiendo sobre la inversión. El modelo responde ante diferentes regímenes cambiarios, políticas monetarias (fijación de metas inflacionarias, fijación de oferta monetaria, adopción o no de esterilización) y grados de apertura financiera (existencia o no de controles de los flujos de capitales).

Supongamos en primer lugar una apertura total de la cuenta de capitales y un régimen cambiario totalmente flexible, es decir, que las ecuaciones [2] y [3] están vigentes. Un incremento de la liquidez financiera internacional, expresado en una caída de la tasa de interés internacional o en un mayor flujo de capitales hacia la región, generará un nuevo equilibrio en los mercados financieros, real y monetario, el que pasará del punto $A$ al $C$ (gráfico 4).

Este nuevo equilibrio supone una mayor oferta de dinero y una caída en la tasa interna de interés, fenómenos que en forma conjunta estimulan el gasto. $\mathrm{Al}$ mismo tiempo, la afluencia de capitales genera expectativas de revaluación cambiaria que continúan hasta que el mercado cambiario y el monetario se ajustan al nuevo equilibrio (recta $r_{1}$ ) del mercado financiero. Si desagregamos la función de inversión en la ecuación de equilibrio en el mercado real tendremos que:

GRAFICO 4

Mercado financiero internacional: Aumento de liquidez

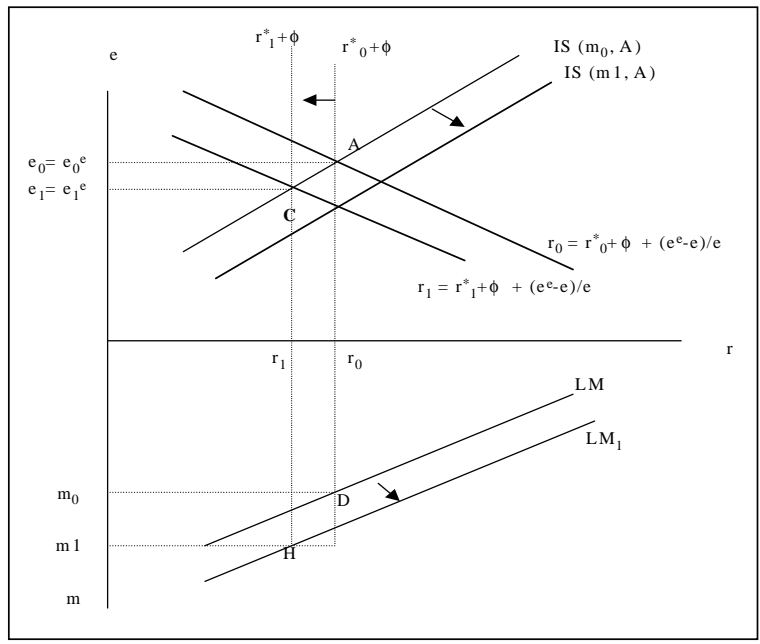

Fuente: CEPAL, División de Desarrollo Económico, elaboración de la autora, 2001. 


$$
I=I(y, r, e)
$$

Tanto el incremento del gasto como la caída de la tasa de interés favorecen la implementación de nuevos proyectos de inversión, mientras que la apreciación cambiaria, si bien reduce el costo de los bienes de capital importados, disminuye la rentabilidad del sector exportador, desalentando así sus proyectos de expansión. El signo final del tipo de cambio real dependerá de las elasticidades y del peso de los distintos sectores en la formación de capital.

$\mathrm{Si}$ en lugar de un incremento de la liquidez financiera internacional se produce un movimiento inverso y por alguna causa exógena los capitales salen de la región, el impacto será el inverso. Si estábamos en un punto como $C$, el incremento de la tasa de interés interna y las expectativas de devaluación cambiaria generarán un nivel de equilibrio con un menor gasto, como el del punto $A$, y el nivel de inversión caerá.

Si el supuesto de perfecta movilidad de capital se sustituye por controles al movimiento de capitales de corto plazo, como sucedió en Chile y Colombia en gran parte de la década de 1990, el efecto de mayor liquidez financiera internacional será menor al observado en el gráfico 4. Los controles del movimiento de capitales actúan como un impuesto al capital, que encarece su costo, disminuye la rentabilidad de los flujos y reduce el gasto. Debido a que el impuesto es selectivo, no siempre afecta directamente a la inversión. Lo que evita es el sobrecalentamiento de la economía y el posterior ajuste. ${ }^{6}$

Las autoridades monetarias pueden también neutralizar el impacto del flujo de capitales con una política de esterilización, esto es, comprando activos internos de forma que se evite la variación de la oferta monetaria. En este caso, se reduce el efecto monetario del incremento en los flujos de capitales y el ajuste en el mercado financiero se produce preferentemente mediante la variación del tipo de cambio real. Por lo tanto, la respuesta específica de la política monetaria influirá en el impacto final sobre la inversión.

$\mathrm{Si}$ en lugar de un régimen de tipo de cambio flexible el país enfrenta un tipo de cambio fijo, los agentes económicos no esperarán una variación en el precio de la moneda nacional frente a la fluctuación de las corrientes de capitales. En este caso, la variable de ajuste en el mercado financiero será la tasa de interés in-

\footnotetext{
${ }^{6}$ Véase al respecto Le Fort y Lehman (2000); De Gregorio, Edwards y Valdés (1999), y Valdés y Soto (1998).
}

terna y, en el mercado monetario, la expansión o contracción de la oferta de dinero que derive de la variación de las reservas.

En el gráfico 5 se muestra el efecto que tiene en el gasto una salida de capitales derivada de una perturbación externa (crisis financiera internacional o regional). Argentina en el 2001 es un buen ejemplo de ese efecto. La salida de capitales genera expectativas de devaluación que situarían el tipo de cambio en $E_{l}$, por encima de $E_{0}$. Estas expectativas trasladan hacia arriba la recta que muestra el equilibrio en el mercado financiero. Al principio, el tipo de cambio inicial permanece en $r_{0}$, inferior a la tasa de rentabilidad esperada de los depósitos en activos externos. Para seguir manteniendo el tipo de cambio, el Banco Central vende reservas, disminuyendo la oferta monetaria y elevando la tasa de interés. El gasto se contrae y también la inversión. La salida de capitales se mantiene hasta que las expectativas de devaluación se detengan y retorne la confianza en la moneda nacional, salvo que, como ocurrió en Argentina, el riesgo-país aumente a causa de la recesión.

Entre los regímenes analizados de tipo de cambio flexible y tipo de cambio fijo (incluido el régimen de convertibilidad), existen casos intermedios, como la intervención de las autoridades cuando el tipo de cambio sobrepasa bandas prefijadas de oscilación. Estos casos intermedios dan origen a ajustes mediante el tipo

GRAFICO 5

América Latina: Fuga de capitales y tipo de cambio fijo

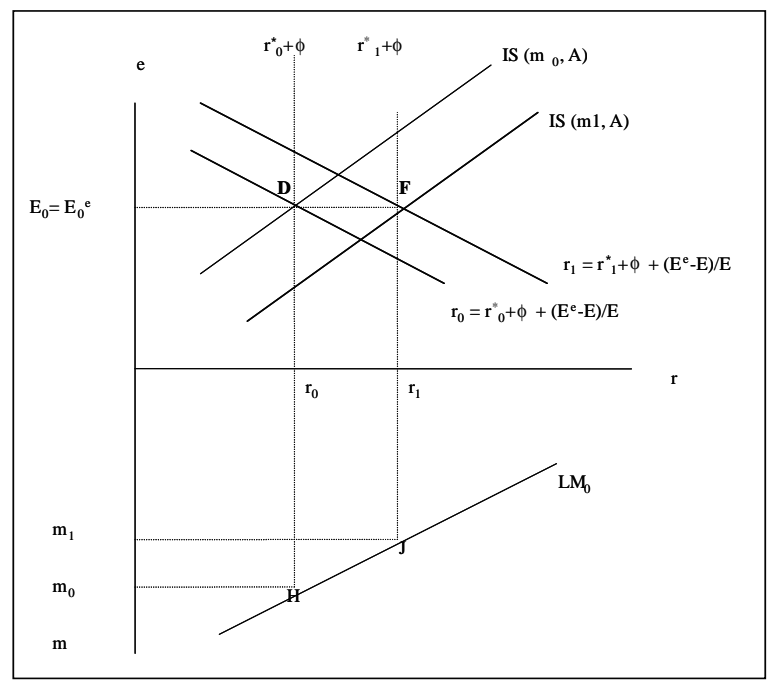

Fuente: CEPAL, División de Desarrollo Económico, elaboración de la autora, 2001 . 
de cambio y la tasa de interés. Los resultados dependerán del grado de confianza de los agentes en las políticas. El caso de Chile después de la crisis asiática (fines de 1997-1998) ilustra el desajuste entre las expectativas de devaluación y la política de defensa del tipo de cambio. Como resultado, hubo incrementos en la tasa de interés que en determinados —aunque breves- momentos superaron el $100 \%$.

Hasta ahora se ha descrito el mecanismo de transmisión de los movimientos exógenos de los flujos de capital hacia las variables macroeconómicas, que a su vez inciden sobre la inversión. El efecto final dependerá del grado de apertura de la cuenta de capitales y de la política monetaria y/o cambiaria de ese momento. Sin embargo, lo mismo que la inestabilidad política o económica (véase Pyndick, 1991), los shocks financieros inesperados afectan el grado de incertidumbre y la disposición al riesgo de los agentes, siendo ésta otra vía por la que la volatilidad de los flujos de capitales afecta la inversión. Al aumentar el grado de incertidumbre, se desalienta la ejecución de los proyectos y se promueve su postergación. En general, las crisis financieras internacionales de los años noventa han mostrado la importancia de considerar la incertidumbre como un factor determinante en la decisión de inversión. Frente a las crisis, los inversionistas financieros entran en pánico, sacando los capitales no sólo del país que está en crisis, sino que de toda una región o del conjunto de los llamados países emergentes. Esto reduce la liquidez de los flujos de corto y de largo plazo, a la vez que genera una mayor incertidumbre en la economía real. ${ }^{7}$

Desde un enfoque microeconómico, la relación entre la volatilidad de los flujos de capital y la inversión es más compleja y no pasa únicamente por la vía indirecta reseñada en el marco macroeconómico. A lo largo de las décadas de 1960 y 1970, quienes sostenían que había vínculos entre el financiamiento y la inversión se bifurcaron en dos escuelas de pensamiento: la poskeynesiana, que mantuvo las ideas originales de Keynes, afirmando que la inestabilidad de las relaciones financieras puede causar volatilidad en la inversión y en la evolución macroeconómica, y la neokeynesiana, cuyo enfoque formal, apoyado en los modelos de optimización derivados de los principios neoclásicos, no incorporó en su desarrollo vínculos importantes entre el financiamiento y la inversión.

\footnotetext{
7 Véase Heymann (2000), sobre aprendizaje en la función de expectativas.
}

En las elaboraciones teóricas de la década de 1980, los "nuevos keynesianos" se abocaron al examen de las imperfecciones de mercado y aplicaron estas ideas al estudio de los mercados de crédito. Por esta vía concluyeron que la capacidad de la empresa para ejecutar los proyectos de inversión depende no sólo de los fundamentos del proyecto sino que también de sus propias condiciones financieras. Esta idea proporcionó nuevos fundamentos para la relación entre la estructura financiera y la actividad real. ${ }^{8}$

Bernanke, Getler y Gilchrist (1996) analizaron la forma en que los cambios en las condiciones del mercado de crédito amplifican y propagan los efectos iniciales de shocks reales o monetarios. Producto del shock, las firmas con una situación debilitada en sus hojas de balance tendrán menor acceso al crédito que las grandes empresas o conglomerados trasnacionales, fenómeno que los autores denominan "huida hacia la calidad". La reorientación de los créditos actúa como un acelerador financiero, aumentando la recesión inicial derivada del shock. Este mismo mecanismo puede darse ante una reversión de los flujos financieros internacionales. En este caso, en lugar de la fuga hacia la calidad que se observa en el sistema financiero nacional, lo que hay es una fuga hacia los países de menor riesgo, con efectos similares sobre las grandes empresas de países emergentes.

El impacto sobre la hoja de balance es transmitido a través del encarecimiento del servicio de la deuda (en moneda nacional y extranjera), la reducción del flujo de caja y el debilitamiento de la posición financiera del deudor. Como muchas empresas dependen fuertemente del endeudamiento de corto plazo para financiar los inventarios y el capital de trabajo, la volatilidad internacional termina teniendo efectos similares sobre el flujo de caja que una política monetaria contractiva. Al mismo tiempo, el alza de la tasa de interés interno - derivada de la restricción de créditos externos- se asocia con una caída del precio de los activos que, entre otras cosas, contrae el valor de las garantías del deudor y su futura capacidad de endeudamiento.

Esto nos lleva a derivar la ecuación siguiente, en la cual el flujo de caja de las empresas $c$ es función del gasto $y$, del costo del capital $r$, de la capacidad de financiamiento interno $m$ y del financiamiento externo $F$.

\footnotetext{
${ }^{8}$ Véase Blinder y Stiglitz (1983); Myers y Majluf (1984); Bernanke y Getler (1995); Bernanke, Getler y Gilchrist (1996); Hubbard (1998); Fazzari, Hobbard y Petersen (1988 y 2000), y Carpenter y otros (1998).
} 


$$
c=f(y, m, r, F)
$$

Tanto en América Latina como en los países en desarrollo en general, las empresas con acceso al mercado internacional de capitales ven extendida su capacidad financiera cuando dicho mercado eleva su liquidez. Esto incide sobre el flujo de caja de las empresas y condiciona la estructura de su financiamiento. El impacto de la reversión de los flujos y/o de la restricción financiera derivada de un shock externo dependerá del grado de endeudamiento externo previo de la empresa, así como de las expectativas alimentadas antes de la crisis. Si la economía venía sobrecalentada y esto indujo a las firmas a sobreinvertir, la reversión repentina de los flujos provocará una subutilización de la capacidad productiva y una reducción de la rentabilidad esperada. Mientras más profunda sea la crisis y más lenta la recuperación, mayores serán las pérdidas y menor la capacidad de financiar la inversión con recursos propios. Si a esto se le suma el deterioro de la capacidad de endeudamiento externo e interno, o un mayor costo del capital, la recuperación de las tasas de inversión será más lenta que su caída, con lo que el efecto de la volatilidad de los flujos será asimétrico.

Este análisis lleva a incluir en la ecuación [6] el efecto directo de la variación de los flujos internacionales de capital derivado de la ecuación [7]. Tendremos así que

$$
I=f(y, r, e)+c(y, m, r, F)-g(u)
$$

donde $u$ representa un indicador de incertidumbre generado por la volatilidad de los flujos de capital.

Obviamente estos factores no afectan por igual a todas las empresas. En América Latina es posible reconocer la existencia de mercados financieros segmentados - por la existencia de mercados incompletos y por la asimetría en la información- y de empresas con diferentes estructuras de financiamiento en términos de componentes de recursos propios, instrumentos de deuda con el sistema financiero nacional o deuda externa. En general, la pequeña y mediana empresa se financia preferentemente con recursos propios y mediante deuda con bancos locales, mientras que la gran empresa nacional y las compañías transnacionales tienen acceso al crédito local y a instrumentos provistos por el mercado financiero internacional: bonos, acciones o deuda externa de mediano y largo plazo.

El acceso a los flujos de capital del sistema financiero internacional, así como la reversión de éstos, afecta por distintas vías a unas y otras empresas, pero también en forma diferenciada a las grandes empresas que apuntan a la exportación o a la producción para el mercado local:

i) Pequeña y mediana empresa: durante el período de crisis, a la caída de la rentabilidad (elemento fundamental para el financiamiento con recursos propios) se suma la restricción del crédito bancario debido a la menor liquidez del mercado financiero local y la menor disposición a asumir riesgos que muestran los bancos. En este sentido opera una especie de mecanismo de desplazamiento (crowding-out) determinado por la huida hacia la calidad reseñada anteriormente. En los períodos de auge, en cambio, la liquidez del sistema financiero interno lleva a los bancos a colocar recursos en actividades que normalmente pudieran ser poco rentables y/o de alto riesgo, produciéndose un fenómeno de complementación (crowding in). Cuando los flujos se revierten, la quiebra de empresas endeudadas en exceso y la fragilidad de las que subsisten hacen que el ciclo financiero se torne más agudo.

ii) Grandes empresas locales o trasnacionales exportadoras: si la afluencia de capitales previa al shock financiero indujo una revaluación cambiaria, la devaluación posterior las beneficiará, abaratando los salarios e insumos en moneda local. Por una parte se elevará su rentabilidad, pero por otra se verá afectada negativamente por la falta de liquidez en el mercado financiero internacional. En general, esto se manifiesta en incapacidad para obtener recursos en forma de bonos, acciones o endeudamiento o en un alto encarecimiento de tales recursos, lo que induce a postergar proyectos de inversión. Lo contrario pasa en períodos de auge, cuando materializar los proyectos de inversión se hace más fácil.

iii) Grandes empresas locales o trasnacionales orientadas al mercado interno: la revaluación del peso en el período de liquidez financiera internacional las beneficia y alienta el endeudamiento externo. Si la empresa anticipa la reversión de los flujos externos o una posible crisis, puede eludir el riesgo cambiario trasladando parte del endeudamiento externo a deuda en moneda local. Si no la anticipa se expondrá a pérdidas por riesgo cambiario. Por otra parte, verá restringido el acceso al financiamiento externo, pero con el agravante de que si se produce una brusca devaluación (porque previamente hubo un tipo de cambio fijo o bandas de flotación sucia), sus ganancias se verán fuertemente disminuidas, con lo que su capacidad crediticia futura se verá afectada. En este caso, las decisiones de inversión no sólo dependerán de los fundamentos del proyecto, sino que también de la evaluación que los 
financistas hagan de la empresa, pudiendo ésta enfrentarse a una restricción crediticia interna y externa.

En síntesis, el efecto de la apertura de la cuenta de capitales y de la volatilidad financiera dependerá del peso de los distintos tipos de empresas en la actividad económica y en la formación de capital. Si predominan las grandes empresas exportadoras, la economía se verá menos afectada, a menos que el destino de las exportaciones esté muy concentrado en mercados que también se hayan visto golpeados por la crisis financiera internacional (éste fue el caso de Chile con la crisis asiática).

También dependerá del grado de endeudamiento interno y externo de las empresas. Si la pequeña y mediana empresa se encuentra muy endeudada en el momento en que se revierten los flujos de capitales y se contrae el gasto, lo más probable es que le cueste mucho sobrevivir. En todo caso, también se demorará en volver a estar en condiciones para ampliar su capacidad productiva en el futuro.

Finalmente, la magnitud del impacto dependerá asimismo de la política monetaria y del régimen cambiario. Diversas experiencias han mostrado que los ajustes con regímenes de tipo de cambio fijo han tenido efectos más traumáticos sobre las variables reales (crecimiento y empleo) que los regímenes de tipo de cambio flexible. ${ }^{9}$ Mientras que el impacto del gasto o el costo del capital sobre la inversión tiene un claro signo (positivo en el primer caso y negativo en el segundo), la variación abrupta del tipo de cambio real tiene un efecto de signo indeterminado sobre la inversión. Ese signo depende del mercado de destino de la producción de las empresas y del tipo de efecto predominante. Si predomina el financiero, la devaluación tiene impacto negativo; si predomina el real, el impacto es indeterminado: por una parte aumenta la rentabilidad de los sectores exportadores, pero por otra se encarece el costo de los bienes de capital, afectando negativamente a las actividades orientadas al mercado interno.

Investigaciones futuras podrán dilucidar los efectos de la volatilidad de los flujos de capital internacional sobre empresas con distinto acceso a ellos, con disímil estructura de financiamiento y orientadas a diferentes sectores: la distinción entre los de exportación y los orientados al mercado local tiene especial relevancia.

\section{VI}

\section{Volatilidad de los flujos de capital e inversión: estimaciones empíricas}

En esta sección se presentan los resultados de la estimación de un modelo econométrico que permite explorar la hipótesis del impacto de la variación y volatilidad de los flujos de capital sobre la inversión. ${ }^{10}$

El mayor peso que los agentes han dado al pasado reciente en la formación de las expectativas futuras, sobre todo con relación a las corrientes de capital, lleva a escoger un modelo de ajuste parcial como especificación pertinente de la ecuación [8]. La forma en que este tipo de modelo estima las expectativas de adaptación a un pasado reciente es consistente con el hecho de que los empresarios no hayan proyectado los puntos de inflexión en la evolución de variables claves - como la interrupción de los flujos o una brusca devaluación-, tendiendo a pensar que la evolución pasada se mantendrá en el futuro. Esto ha hecho que las crisis externas los hayan tomado desprevenidos y en muchos casos sobreinvertidos.
Debido a que las variables en nivel están expuestas a una correlación espuria por el fuerte impacto de la tendencia, en la estimación del modelo se consideran las variables explicativas en diferencias.

En la definición de flujos de capital no se incluye la inversión extranjera directa. La razón es que una parte de lo que se registra como tal es inversión nueva incorporada a la formación bruta de capital de los países, y en este sentido es un componente y no un determinante de la inversión —está al lado izquierdo y no al derecho de la ecuación-. El resto, correspon-

\footnotetext{
${ }^{9}$ Véase al respecto Ffrench-Davis y Larraín (2001).

10 Aunque el modelo intenta resaltar explícitamente los factores financieros como determinantes de la inversión, también considera otros elementos presentes en estimaciones empíricas para países de América Latina en las tres últimas décadas. Véase al respecto Serven y Solimano (1993); Rama (1993); Moguillansky (1996) y Agosin (1997).
} 
Recuadro 1

ESPECIFICACIÓN DEL MODELO DE INVERSIÓN REGIONAL

$$
\text { I_Y }=\mathrm{c}(1) \Delta \mathrm{PIB}+\mathrm{c}(2) \Delta \mathrm{XM} \_\mathrm{Y}+\mathrm{c}(3) \Delta \mathrm{TCR}+\mathrm{c}(4) \Delta \mathrm{VTCR}+\mathrm{c}(5) \Delta(\mathrm{OK})+\mathrm{c}(6) \Delta \mathrm{VF}+\mathrm{c}(7) \text { I_Y }(-1)
$$

Donde:

I_Y : Coeficiente de inversión sobre el PI.

PIB : Producto interno bruto.

XM_Y : Corresponde al peso del comercio exterior (exportaciones más importaciones), sobre el PIB.

TCR : Índice del tipo de cambio real.

VTCR : Indicador de volatilidad anual del tipo de cambio real, calculado sobre la base del coeficiente de variación del tipo de cambio real mensual.

OK : Transferencia neta de recursos del exterior como porcentaje del PIB, excluida la inversión extranjera directa.

VF : Indicador de volatilidad de los flujos de capital. Corresponde a la variación anual de un promedio móvil del coeficiente de variación de los flujos de transferencias netas de recursos, calculados sobre una base quinquenal.

$\Delta \quad$ : Operador Delta; representa la primera diferencia de la variable.

Fuente: CEPAL, División de Desarrollo Económico, elaboración de la autora, 2001.

diente al pago por compra de activos, representa transferencia de capital y no formación del mismo, por lo tanto tampoco corresponde considerarlo como determinante de la inversión.

Respecto de la volatilidad de los flujos se consideró el conjunto de transferencias netas de recursos externos. En los períodos de crisis internas y de shocks externos se produce una caída general de todos los componentes del financiamiento externo, y es justamente este comportamiento el que deprimiría la inversión. Como un indicador complementario que alimenta el grado de incertidumbre, incluimos en el modelo la volatilidad del tipo de cambio real. Su signo sería negativo, como el de la volatilidad de los flujos de capital.

El modelo considera además dos variables de control. La primera es la apertura comercial, medida por la participación del comercio exterior - exportaciones más importaciones- en el PIB. La apertura se consideró una medida fundamental para estimular las exportaciones, al abaratar los insumos y bienes de capital importados. Indirectamente, tendría un influjo positivo sobre la inversión

La segunda variable de control considerada es una variable ficticia para la década de 1980, que recoge la depresión inducida en la inversión durante la crisis de la deuda externa y el proceso de ajuste posterior hasta la recuperación.
La estimación del modelo se llevó a cabo mediante el método de panel, considerando un total de 16 países de América Latina para los cuales se dispone de variables homogéneas y datos anuales que cubren el período 1970-2000. Se utilizaron dos métodos de estimación con coeficientes fijos. El primero, a través de mínimos cuadrados generalizados, incorporando la matriz de covarianzas y errores estándares consistentes obtenida con el método de White (1980). El segundo, usando un estimador consistente para la presencia tanto de heterocedasticidad como de autocorrelación serial de los errores. En este caso se utilizó el método de regresión aparentemente no relacionada SUR (seemingly unrelated regression).

El cuadro 4 presenta los coeficientes de las regresiones de panel, asumiéndose efectos fijos y coeficientes comunes para las variables explicativas, es decir, que la función de inversión de los diferentes países presenta las mismas elasticidades. Los signos de las variables son los esperados y los coeficientes son robustos cuando se aplican los diferentes métodos de estimación.

Los resultados muestran que en el conjunto de la región, y sobre la base de información estadística acerca de 16 países, es posible identificar entre los determinantes de la inversión el impacto significativo de la liquidez de recursos financieros externos, así como de su volatilidad. La variación en la disponibilidad de 


\begin{tabular}{|c|c|c|c|c|}
\hline \multirow{3}{*}{$\begin{array}{l}\text { Variable dependiente: I_Y } \\
\text { Variables explicativas: }\end{array}$} & \multicolumn{4}{|c|}{ Corrección de } \\
\hline & \multicolumn{2}{|c|}{$\begin{array}{c}\text { Heterocedasticidad } \\
\text { (White, 1980) }\end{array}$} & \multicolumn{2}{|c|}{$\begin{array}{c}\text { Autocorrelación y } \\
\text { heterocedasticidad (SUR) }\end{array}$} \\
\hline & Coeficiente & $\begin{array}{l}\text { Estadística } \\
\text { t de Student }\end{array}$ & Coeficiente & $\begin{array}{l}\text { Estadística } \\
\mathrm{t} \text { de Student }\end{array}$ \\
\hline$\Delta \mathrm{PIB}(-1)$ & 0.0076 & 7.62 & 0.0077 & 11.92 \\
\hline$\Delta X M \_Y$ & 0.0019 & 4.72 & 0.0019 & 9.21 \\
\hline$\Delta$ XM_Y $(-1)$ & 0.0778 & 2.03 & 0.0528 & 2.39 \\
\hline$\Delta \mathrm{TCR}$ & -0.0172 & -4.21 & -0.0166 & -8.48 \\
\hline$\Delta \operatorname{VTCR}(-1)$ & -0.0002 & -0.03 & -0.0016 & -0.57 \\
\hline$\Delta \mathrm{OK}$ & 0.0064 & 4.74 & 0.0061 & 11.60 \\
\hline$\Delta \mathrm{VF}(-1)$ & -0.0011 & -3.49 & -0.0011 & -5.35 \\
\hline D8189 & -0.0186 & -2.15 & -0.0291 & -5.09 \\
\hline I_Y $(-1)$ & 0.8262 & 34.76 & 0.8111 & 44.05 \\
\hline
\end{tabular}

Fuente: CEPAL, División de Desarrollo Económico, elaboración de la autora, sobre la base de los apéndices 1 y 2.

capitales externos y/o sus bruscos cambios de signo son captados por la evolución de la inversión agregada, a partir del efecto microeconómico que es transmitido por el deterioro de la capacidad de endeudamiento externo de las grandes empresas, por la fuga hacia la calidad en el sistema financiero nacional - lo que redunda en restricción crediticia para la mediana y pequeña empresa - y por el aumento de la incertidumbre de los agentes económicos.

El modelo estima que por la vía directa de la contracción del financiamiento, una reversión de un $1 \%$ del PIB en los flujos de capital reduce $0.64 \%$ la participación de la inversión en el producto regional en el corto plazo. Si esa reversión de los flujos aumenta su volatilidad, provocando en los agentes económicos un mayor grado de incertidumbre, el resultado podría expresarse en una caída adicional de $0.11 \%$ en el coeficiente de inversión. Estos impactos directos no consideran el efecto que tiene la reversión de los flujos sobre el gasto, recogido del modelo estimado por el acelerador keynesiano, y sobre el tipo de cambio real (encarecimiento de los bienes de capital importados). Un modelo estructural mostraría este doble impacto.

\section{VII}

\section{Síntesis y conclusiones}

La liberalización financiera y del mercado de capitales permitió atraer la inversión extranjera y expandir en general la capacidad de financiar los proyectos de inversión, pero a la vez facilitó la difusión de las crisis financieras originadas dentro o fuera de América Latina. Estas crisis, que en el transcurso de la década de 1990 se sucedieron con mayor frecuencia, interrumpieron repetidamente el crecimiento y el financiamiento, lo que llevó a estudiar con mayor detenimiento el impacto de la inestabilidad de los flujos de capital sobre la inversión.

Un primer hecho estilizado que destaca este artículo es que la apertura del mercado de capitales tuvo como resultado un cambio en la composición de las corrientes internacionales de capital hacia la región. En ellas los recursos oficiales se redujeron de un $23 \%$ en 1970 hasta un monto ínfimo en el año 2000. Por otra parte, la inversión extranjera directa pasó a liderar los flujos privados, promediando cerca de un $40 \%$ a mediados de los años noventa y un $74 \%$ en 2000 ; sin embargo, en los últimos años menos del $50 \%$ de esa inversión se ha orientado a la formación física de capital. El resto ha correspondido a una mera transferencia de activos - esto es, a pagos por privatizaciones, adquisiciones o fusiones-, fenómeno que se inserta en una ola de concentración de capital prevaleciente en el mundo. Dado que el coeficiente de inversión regional ha estado cayendo en los últimos años, es 
posible que la contraparte de estos flujos - los pagos por compra de empresas- esté siendo invertida fuera de la región.

El otro fenómeno estilizado es la alta volatilidad experimentada por las corrientes de capitales externos diferentes de la inversión extranjera directa. Ellas corresponden a un conjunto de recursos de diverso origen, como inversiones de cartera en la forma de acciones y bonos; créditos de corto plazo, y créditos de largo plazo de la banca internacional (en algunos casos asociados a la inversión extranjera directa), que han tenido la particularidad de presentar una alta liquidez en ciertos períodos (sobre todo previos a la crisis del tequila y a la crisis asiática) y de retirarse abruptamente en medio de las crisis, generando graves problemas financieros y de solvencia en algunos países de la región.

Del análisis de los mecanismos por los cuales se transmite el impacto de los flujos de capital y de su volatilidad sobre la inversión se desprende que, a nivel macroeconómico, estas variables afectan la tasa interna de interés, las expectativas de devaluación o revaluación del tipo de cambio, las presiones inflacionarias y el efecto que todo ello en conjunto genera sobre el gasto. Sin embargo, la magnitud del impacto dependerá del régimen cambiario imperante (el que no sólo difiere entre los países de la región, sino también entre distintos períodos dentro de un mismo país); de la política monetaria (existencia o no de metas inflacionarias, de fijación de la oferta o de políticas de esterilización) y del grado de apertura financiera (existencia o no de controles sobre los flujos de capitales). La forma en que se combinan estas políticas crea un contexto de mayor o menor vulnerabilidad frente a una súbita escasez de capitales o frente a una crisis financiera internacional.

Fuera de los mecanismos de transmisión macroeconómicos descritos, existe un mecanismo de transmisión microeconómico que amplifica y propaga los efectos iniciales de los shocks monetarios o financieros, sirviendo de "acelerador financiero". Este mecanismo actúa por dos vías:

i) mediante el mayor acceso a crédito externo barato y menores restricciones al otorgamiento de créditos, en los períodos de auge, y mediante la "huida hacia la calidad", es decir, la reorientación del financiamiento internacional hacia países de menor riesgo, frente a una crisis financiera dentro o fuera de la región. La consecuencia es una proliferación o una reducción abrupta de la ejecución de los grandes proyectos de inversión en los países emergentes; ii) a través de un proceso de desplazamiento (crowding out) en caso de crisis, y uno de complementación (crowding in) en períodos de auge. En el primer caso, la banca concentra los créditos en la gran empresa y desplaza del financiamiento a la empresa pequeña y mediana, que resulta especialmente perjudicada en tiempos de baja liquidez internacional. En el segundo caso, el hecho de que la gran empresa disponga de financiamiento externo abre espacio en el mercado bancario nacional al financiamiento de la pequeña empresa. Tanto la "huida hacia la calidad" en materia de financiamiento externo, como el desplazamiento en el sistema financiero interno, agudizan la recesión inicial derivada de una crisis financiera internacional. Por otra parte, el sobreendeudamiento observado en la pequeña y la gran empresa en los períodos de fuerte liquidez financiera contribuye a agudizar la crisis cuando las corrientes se revierten.

Al igual que la inestabilidad política o económica, los shocks financieros inesperados afectan el grado de certidumbre y la disposición a asumir riesgos de los agentes, siendo ésta otra vía por la cual la volatilidad de los flujos de capitales afecta a la inversión. Al aumentar el grado de incertidumbre se desalienta la ejecución de proyectos, sobre todo de aquéllos cuyos retornos se esperan a un mayor plazo. Entre éstos se encuentran los grandes proyectos de infraestructura, los que antes de las privatizaciones eran financiados parcialmente con créditos de organismos multilaterales y ejecutados por el Estado, como parte de políticas anticíclicas.

Para apreciar cuán generalizadas son en América Latina tanto la volatilidad financiera como la incertidumbre que ésta conlleva, se estimó un modelo de panel que considera 16 países de la región, cuyas estadísticas cubren el período 1970-2000. La especificación asumió la forma de un modelo de ajuste parcial, intentando así recoger el aprendizaje de los agentes en torno a la función de expectativas. Esta es consistente con el hecho de que los empresarios no hayan proyectado los puntos de inflexión en la evolución de los flujos de capital y de los regímenes cambiarios, lo que ha hecho que las crisis externas los tomen en muchos casos desprevenidos y sobreinvertidos. Además de las variables relacionadas con el impacto de la volatilidad del financiamiento externo, el modelo incluye aquéllas que normalmente se han considerado como determinantes de la inversión en estimaciones empíricas regionales.

Los resultados muestran coeficientes significativos de variación en la liquidez de recursos financieros externos y en su volatilidad. El modelo estima que una 
reversión de un 1\% del PIB en los flujos de capital hace, por la vía directa de la contracción del financiamiento, que la participación de la inversión en el producto regional caiga $0.64 \%$. Si esta reversión en los flujos aumenta su grado de volatilidad, provocando en los agentes económicos un mayor grado de incertidumbre, el resultado podría expresarse en una caída adicional de $0.11 \%$ en el coeficiente de inversión. Esto sin considerar el efecto que la reversión de los flujos genera sobre el gasto, recogido en el modelo por el acelerador keynesiano, y sobre el tipo de cambio real.

Hay que tener en cuenta que no todas las empresas tienen acceso a los recursos del sistema financiero internacional, y que el impacto de una reversión imprevista de los flujos depende del grado de endeudamiento interno o externo de ellas, así como del grado de sobrecalentamiento previo de la economía, de la política monetaria y del régimen cambiario imperante en el momento de la crisis. Esto lleva a concluir que el efecto de la volatilidad en el movimiento internacional de capitales será diferenciado no sólo entre empresas, sino que también entre países.

En resumen, el ejercicio muestra que la apertura al mercado internacional de capitales tiene un efecto favorable sobre la inversión regional en los períodos de liquidez financiera, pero que la inestabilidad y volatilidad de los flujos hace de ella un arma de doble filo. Una forma de mitigar los efectos negativos es incorporar barreras a la entrada de capitales en períodos de fuerte liquidez — esta medida se aplicó con éxito en Chile en ciertos momentos-, evitando el sobrecalentamiento de la economía. ${ }^{11}$ Otra alternativa es aplicar políticas macroeconómicas (fiscales y monetarias) anticíclicas, aun en el ámbito restringido por la globalización. Si el país está expuesto a una trampa de liquidez, exhibe un sistema financiero poco solvente o mantiene un régimen de tipo de cambio fijo en un contexto de plena apertura del mercado de capitales, la política monetaria será ineficaz y en ese caso la política anticíclica deberá basarse en el instrumento fiscal. Para esto es preciso contar con instituciones más sólidas, mayor independencia y una política fiscal más flexible que la existente hoy en los países latinoamericanos. Finalmente, la defensa del acceso al crédito de la pequeña y mediana empresa en momentos de crisis sugiere la necesidad de revisar la legislación financiera y el papel de la banca de desarrollo.

${ }^{11}$ Véase al respecto Valdés y Soto (1998); De Gregorio, Edwards y Valdés (1999); Le Fort y Lehman (2000).

APENDICE A

Resultados de la estimación del modelo regional: Corrección de heterocedasticidad mediante la matriz de covarianzas de White

Muestra:

Variable dependiente:

Número de observaciones seriales:

Número de observaciones totales del panel balanceado:
1977-2000

I_Y

24

384

\begin{tabular}{|c|c|c|c|c|}
\hline Variable & Coeficiente & Error estándar & Estadística t & Prob. \\
\hline$\Delta \_$PIB $(-1)$ & 0.0076 & 0.0010 & 7.62 & 0.000 \\
\hline$\Delta \mathrm{XM} Y \mathrm{Y}$ & 0.0019 & 0.0004 & 4.72 & 0.000 \\
\hline$\Delta \mathrm{XM}_{-}^{-} \mathrm{Y}(-1)$ & 0.0778 & 0.0382 & 2.03 & 0.042 \\
\hline$\Delta \_\mathrm{TCR}$ & -0.0172 & 0.0041 & -4.21 & 0.000 \\
\hline$\Delta \_$VTCR $(-1)$ & -0.0002 & 0.0061 & -0.03 & 0.973 \\
\hline$\Delta \overline{\mathrm{OKK}}$ & 0.0064 & 0.0013 & 4.74 & 0.000 \\
\hline$\Delta \mathrm{VF}(-1)$ & -0.0011 & 0.0003 & -3.49 & 0.000 \\
\hline D8189 & -0.0186 & 0.0086 & -2.15 & 0.031 \\
\hline I_Y (-1) & 0.8263 & 0.0238 & 34.76 & 0.000 \\
\hline
\end{tabular}

Efectos fijos

$\begin{array}{ll}\text { Argentina-c } & 0.3126 \\ \text { Bolivia-c } & 0.3333 \\ \text { Brasil-c } & 0.3238 \\ \text { Chile-c } & 0.2775 \\ \text { Colombia-c } & 0.3367\end{array}$


Apéndice A (continuación)

\begin{tabular}{|c|c|c|c|}
\hline Variable & Coeficiente & Error estándar & Prob. \\
\hline Costa Rica-c & 0.2957 & & \\
\hline Rep. Dominicana-c & 0.2762 & & \\
\hline Ecuador-c & 0.3415 & & \\
\hline El Salvador-c & 0.3374 & & \\
\hline Guatemala-c & 0.4098 & & \\
\hline Honduras $-\mathrm{c}$ & 0.2836 & & \\
\hline México-c & 0.3198 & & \\
\hline Paraguay $-\mathrm{c}$ & 0.3008 & & \\
\hline Perú-c & 0.2942 & & \\
\hline Uruguay-c & 0.3641 & & \\
\hline Venezuela-c & 0.3274 & & \\
\hline \multicolumn{4}{|l|}{ Estadísticas ponderadas } \\
\hline $\mathrm{R}^{2}$ & 0.96 & Media de la var. dependiente & -1.80 \\
\hline $\mathrm{R}^{2}$ ajustado & 0.95 & Desviac. estánd. de la var. dep. & 0.42 \\
\hline Suma los cuadrados de la regresión & 0.08 & Suma de cuadr. de residuos & 2.79 \\
\hline Probabilidad logarítmica & 412 & Estadística F & 1089 \\
\hline Estadística de Durbin-Watson & 1.97 & Prob. (estadística F) & 0.00 \\
\hline \multicolumn{4}{|l|}{ Estadísticas sin ponderar } \\
\hline $\mathrm{R}^{2}$ & 0.90 & Media de la var. dependiente & -1.72 \\
\hline $\mathrm{R}^{2}$ ajustado & 0.90 & Var. estándar de la var. dep. & 0.28 \\
\hline Suma de los cuadrados de la regresión & 0.08 & Suma de cuadr. de residuos & 2.81 \\
\hline Estadística de Durbin-Watson & 1.92 & & \\
\hline
\end{tabular}

Fuente: CEPAL, División de Desarrollo Económico, elaboración de la autora.

APENDICE B

Resultados de la estimación del modelo regional: Corrección de heterocedasticidad y de la autocorrelación en los errores, método sUR ${ }^{\mathrm{a}}$

Muestra:

1977-2000

Variable dependiente:

I_Y

Número de observaciones seriales:

384

Número de observaciones totales del panel balanceado:

\begin{tabular}{|c|c|c|c|c|}
\hline Variable & Coeficiente & Error estándar & Estadística t & Prob. \\
\hline$\Delta \_$PIB (-1) & 0.0076 & 0.0010 & 7.62 & 0.000 \\
\hline$\Delta \mathrm{XM} Y \mathrm{Y}$ & 0.0019 & 0.0004 & 4.72 & 0.000 \\
\hline$\Delta X M \_Y(-1)$ & 0.0528 & 0.0220 & 2.39 & 0.017 \\
\hline$\Delta \mathrm{TCR}$ & -0.0166 & 0.0019 & -8.48 & 0.000 \\
\hline$\Delta \_$VTCR $(-1)$ & -0.0016 & 0.0026 & -0.57 & 0.562 \\
\hline$\Delta \overline{\mathrm{OK}}$ & 0.0060 & 0.0005 & 11.60 & 0.000 \\
\hline D8189 & -0.0290 & 0.0057 & -5.09 & 0.000 \\
\hline I_Y (-1) & 0.8111 & 0.0184 & 44.05 & 0.000 \\
\hline
\end{tabular}

Efectos fijos

Argentina-c

Bolivia-c

0.356

Brasil-c

0.343

Chile-c

0.295

Colombia-c

0.358 
Apéndice $B$ (continuación)

\begin{tabular}{|c|c|c|c|c|}
\hline Variable & \multirow{2}{*}{$\begin{array}{c}\text { Coeficiente } \\
0.313\end{array}$} & \multirow[t]{2}{*}{ Error estándar } & \multirow[t]{2}{*}{ Estadística t } & \multirow[t]{2}{*}{ Prob. } \\
\hline Costa Rica-c & & & & \\
\hline Rep. Dominicana-c & 0.293 & & & \\
\hline Ecuador $-\mathrm{c}$ & -0.364 & & & \\
\hline El Salvador-c & -0.359 & & & \\
\hline Guatemala-c & -0.438 & & & \\
\hline Honduras- $\mathrm{c}$ & -0.302 & & & \\
\hline México-c & -0.337 & & & \\
\hline Paraguay $-\mathrm{c}$ & -0.318 & & & \\
\hline Perú-c & -0.311 & & & \\
\hline Uruguay-c & -0.388 & & & \\
\hline Venezuela-c & -0.347 & & & \\
\hline Probabilidad logarítmica & & & & \\
\hline \multicolumn{5}{|l|}{ Estadísticas sin ponderar } \\
\hline $\mathrm{R}^{2}$ & 0.90 & Media de la va & ente & -1.72 \\
\hline $\mathrm{R}^{2}$ ajustado & 0.90 & Desv. estándar & dep. & 0.28 \\
\hline Suma de los cuadrados de la regresión & 0.08 & Suma de cuadr & & 2.81 \\
\hline Estadística de Durbin-Watson & 1.89 & & & \\
\hline
\end{tabular}

Fuente: CEPAL, División de Desarrollo Económico, elaboración de la autora.

a SUR: Regresión aparentemente no relacionada (seemingly unrelated regression).

\section{Bibliografía}

Agosin, M. (1997): Entrada de capitales y desempeño de la inversión: Chile en los años noventa, en R. Ffrench Davis y H. Reisen (comps.), Flujos de capital e inversión productiva: lecciones para América Latina, Santiago de Chile, Comisión Económica para América Latina y el Caribe (CEPAL).

Banco Mundial (2001): Global Development Finance, Washington, D.C.

Bernanke, B. y M. Getler (1995): Inside the black box: The credit channel of monetary policy transmission, Journal of Economic Perspective, vol. 9, $\mathrm{N}^{\circ} 4$, Nashville, Tennessee, American Economic Association.

Bernanke, B., M. Getler y S. Gilchrist (1996): The financial accelerator and the flight to quality, The Review of Economics and Statistics, vol. 78, $\mathrm{N}^{\circ} 1$, Cambridge, Massachusetts, The MIT Press.

Blinder, A. y J. Stiglitz (1983): Money, credit constraints and economic activity, American Economic Review, vol. 73, $\mathrm{N}^{\circ} 2$, Nashville, Tennessee, American Economic Association.

Carpenter, R. y otros (1998): Financing constraints and inventory investment: A comparative study with high-frequency panel data, Review of Economics and Statistics, vol. 80, $\mathrm{N}^{\circ} 4$, Cambridge, Massachusetts, The MIT Press.

CEPAL (2001): La inversión extranjera en América Latina y el Caribe; informe 2000, LC/G.2125-P, Santiago de Chile.

Claassen, E. (1997): Global Monetary Economics, Nueva York, Oxford University Press.

Claessens, S., M. Dooley y A. Warner (1995): Portfolio capital flows: Hot or cold?, The World Bank Economic Review, vol. 9, $\mathrm{N}^{\circ} 1$, Washington, D.C., Banco Mundial.

De Gregorio, J., S. Edwards y R. Valdés (1999): Capital controls in Chile: An assesment, Santiago de Chile, Banco Central de Chile, inédito.
Edwards, S. (1995): Crisis and Reform in Latin America, from Despair to Hope, Nueva York, Oxford University Press.

Fazzari, S., R. Hobbard y B. Petersen (1988): Financing constraints and corporate investment, Brookings Papers on Economic Activity, $\mathrm{N}^{\circ} 1$, Washington, D.C., The Brookings Institution. (2000): Investment-cash flow sensitivities are useful: A comment on Kaplan and Zingales, Quarterly Journal of Economics, vol. 115, $\mathrm{N}^{\circ}$ 2, Cambridge, Massachusetts, The MIT Press.

Ffrench-Davis, R. (comp.) (2001): Crisis financieras en países 'exitosos', Santiago de Chile, CEPAL/Mc Graw-Hill Interamericana.

Ffrench-Davis, R. y G. Larraín (2001): How optimal are the extremes? Latin America exchange rate after the Asian crisis, Santiago de Chile, inédito.

Ffrench-Davis, R. y J. A. Ocampo (2001): Globalización de la volatilidad financiera: desafíos para las economías emergentes, en R. Ffrench-Davis (comp.), Crisis financieras en países 'exitosos', Santiago de Chile, CEPAL/McGraw Hill Interamericana.

Ffrench-Davis, R. y H. Reisen (comps.) (1998): Capital Flows and Investment Performance: Lessons from Latin America, París, Organización de Cooperación y Desarrollo Económicos (OCDE).

Frenkel, R. (1982): Mercado financiero, expectativas cambiarias y movimientos de capital, Desarrollo económico, vol. 22, $\mathrm{N}^{\circ}$ 87, Buenos Aires, Instituto de Desarrollo Económico y Social (IDES).

Frenkel, R. y M. Damill (1987): De la apertura a la crisis financiera. Un análisis de la experiencia argentina de 1977-1982, Ensayos económicos, $N^{\circ} 37$, Buenos Aires, Banco Central de la República Argentina. 
Hausmann, R. y E. Fernández-Arias (2000a): Is FDI a Safer Form of Financing?, Working papers, $\mathrm{N}^{\circ} 416$, Washington, D.C., Banco Interamericano de Desarrollo (BID).

(2000b): Foreign Direct Investment: Good Cholesterol?, Working papers, $\mathrm{N}^{\circ} 417$, Washington, D.C., Banco Interamericano de Desarrollo (BID).

Heymann, D. (2000): Grandes perturbaciones macroeconómicas, expectativas y respuestas de política, Revista de la CEPAL, $\mathrm{N}^{\circ} 70$, LC/G.2095-P, Santiago de Chile, CEPAL.

Hofman, A. (en prensa): Capital Formation, Employment and Potential Output in Latin America: A Simplified Econometric Approach for the 1950-2000 Period, Santiago de Chile.

Hubbard, G. (1998): Capital market imperfections and investment, Journal of Economic Literature, vol. 36, $\mathrm{N}^{\circ}$ 1, Nashville, Tennessee, American Economic Association.

Kosacoff, B. (1998): Estrategias empresariales y ajuste industrial, Buenos Aires, Oficina de la CEPAL en Buenos Aires.

Krugman, P. y M. Obstfeld (1995): Economía internacional, Madrid, McGraw Hill.

Le Fort, G. y S. Lehman (2000): El encaje, los flujos de capitales y el gasto: una evaluación empírica, Documentos de trabajo, $\mathrm{N}^{\circ}$ 64, Santiago de Chile, Banco Central de Chile.

Lipsey, R. (2001): Foreign Direct Investment in Three Financial Crises, Working papers, $\mathrm{N}^{\circ} 84$, Cambridge, Massachusetts, National Bureau of Economic Research (NBER).

Moguillansky, G. (1996): El contexto macroeconómico y la inversión: América Latina a partir de 1980, Revista de la CEPAL, N58, LC/G.1916-P, Santiago de Chile, CEPAL.

Moguillansky, G. y R. Bielschowsky (2000): Inversión y reformas económicas en América Latina, Santiago de Chile, Fondo de Cultura Económica/CEPAL.

Morley, S., R. Machado y S. Pettinato (1999): Indexes of Structural Reform in Latin America, Serie reformas económicas, No.12, Santiago de Chile, CEPAL.

Myers, S. N. y N. Majluf (1984): Corporate financing and investing decisions when firms have information that investors do not have, Journal of Financial Economics, $\mathrm{N}^{\circ} 3$.

Ocampo, J. A. (coord.) (2000): Crecer con estabilidad. El financiamiento del desarrollo en el nuevo contexto internacional, LC/ G.2117, Santiago de Chile, CEPAL.
Ocampo, J. A. y C. Tovar (1999): Price-Based Capital Account Regulations: The Colombian Experience, serie Financiamiento del desarrollo, $N^{\circ} 87$, Santiago de Chile, CEPAL.

Ocampo, J. A., R. Bajraj y J. Martin (coords.) (2001): Una década de luces y sombras: América Latina y el Caribe en los años noventa, Santiago de Chile, CEPAL/Alfaomega.

Pyndick, R. S. (1991): Irreversibility, uncertainty, and investment, Journal of Economic Literature, vol. XXIX, $\mathrm{N}^{\circ} 3$, Nashville, Tennessee, American Economic Association.

Rama, M. (1993): Empirical investment equations for developing countries, en L. Serven y A. Solimano (eds.), Striving for Growth after Adjustment: The Role of Capital Formation, Washington, D. C., Banco Mundial.

Sarno, L. y M. P. Taylor (1999): Hot money, accounting labels and the permanence of capital flows to developing countries: An empirical investigation, Journal of Development Economics, vol. 59, $\mathrm{N}^{\circ}$ 2, Amsterdam, Países Bajos, Elsevier Science Publishers, B.V.

Serven, L. y A. Solimano (eds.) (1993): Striving for Growth after Adjustment: The Role of Capital Formation, Washington, D.C., Banco Mundial.

Stiglitz, J. E. y A. Weiss (1981): Credit rationing in markets with imperfect information, American Economic Review, vol. 71, $\mathrm{N}^{\circ} 3$, Nashville, Tennessee, American Economic Association.

Uthoff A. y D. Titelman (1997): La relación entre ahorro externo y el ahorro nacional en contextos de liberación financiera, en R. Ffrench-Davis y H. Reisen (comps.), Flujos de capital e inversión productiva: lecciones para América Latina, Santiago de Chile, CEPAL.

Valdés, S. y M. Soto (1998): ¿Es el control selectivo de capitales efectivo en Chile? Su efecto sobre el tipo de cambio real, Cuadernos de economía, año 33, $\mathrm{N}^{\circ} 98$, Santiago de Chile, Pontificia Universidad Católica de Chile.

Villar, L. (2000): Manejo de auge y crisis financieras internacionales, en CEPAL, Hacia un sistema financiero internacional estable y predecible y su vinculación con el desarrollo social, serie Temas de coyuntura, $\mathrm{N}^{\circ} 8$, Santiago de Chile.

White, H. (1980): A heteroskedasticity-consistent covariance matrix estimator and a direct test for heteroskedasticity, Econometrica, vol. 48, $\mathrm{N}^{\circ} 4$, Evanston, Illinois, The Econometric Society. 